\title{
Penghambatan Interaksi Eutektik Akibat Energi Kompresi dengan Penambahan Pati Jagung
}

(Inhibition of eutectic interaction upon compression by corn starch addition)

\author{
Dwi Setyawan ${ }^{*}$ Noorma Rosita, Diajeng Putri Paramita, \& Dicky \\ Pratama
}

Departemen Farmasetika, Fakultas Farmasi Universitas Airlangga

\begin{abstract}
This research has been carried out to study inhibition of eutectic interaction which occurs on compressed binary mixture of ibuprofen-stearic acid by addition of corn starch. Corn starch was mixed into binary mixture of 40:60 (\% w/w) ibuprofenstearic acid with composition of 10,20 , and $30 \%(w / w)$ and then compressed into tablet form. The physical characterization was conducted using tensile strength test, differential thermal analysis (DTA), powder X-ray diffraction (PXRD), fourier transform infrared (FT-IR), and scanning electron microscope (SEM). According to tensile strength test, the value was reduced upon addition of 10 and $20 \%$ corn starch compared to the compressed binary mixture. Addition $20 \%$ corn starch to compressed binary mixture shifted the eutectic diffraction peaks with a decline in intensity during PXRD study. Thermal analysis of compressed binary mixture-20\% corn starch exhibited an increase in eutectic point, and FT-IR spectrum was observed no difference compared to the compressed binary mixture. SEM analysis indicated that $20 \%$ corn starch addition was able to inhibit sintering phenomena by dispersed on particle's surfaces. Physical characterizations result in the conclusion that corn starch can inhibit the eutectic interaction between ibuprofen and stearic acid upon compression.
\end{abstract}

Keywords: ibuprofen; stearic acid; compression; eutectic; corn starch; physical characterization.

ABSTRAK: Penelitian ini dilakukan untuk mengetahui penghambatan interaksi eutektik yang terjadi pada pengempaan campuran biner ibuprofen-asam stearat dengan penambahan pati jagung. Pati jagung ditambahkan ke dalam campuran biner ibuprofenasam stearat 40:60 (\% b/b) dengan komposisi 10, 20, dan 30\% (b/b) kemudian dikempa. Karakterisasi fisik tablet kempa dilakukan menggunakan analisis kekuatan mekanik, differential thermal analysis (DTA), difraksi sinar-X serbuk (DSXS), spektroskopi fourier transform infrared (FT-IR), dan scanning electron microscope (SEM). Uji kekuatan mekanik menunjukkan penambahan pati jagung 10 dan 20\% menyebabkan penurunan nilai kekuatan tarik dibandingkan campuran biner. Penambahan 20\% pati jagung menyebabkan pergeseran puncak ke sudut $2 \theta$ lebih besar disertai dengan penurunan intensitas difraksi sinar-X. Analisis termal tablet kempa campuran biner-pati jagung 20\% menunjukkan peningkatan titik lebur eutektik dan spektra FT-IR yang dihasilkan tidak berbeda dibandingkan dengan tablet kempa campuran biner. Fotomikrograf SEM menunjukkan penambahan pati jagung $20 \%$ dapat mencegah terjadinya sintering pada tablet kempa ibuprofen-asam stearat. Hasil karakterisasi fisik mengindikasikan bahwa pati jagung dapat meredam pembentukan eutektik akibat energi kompresi antara ibuprofen-asam stearat pada komposisi $20 \%(b / b)$.

Kata kunci: ibuprofen; asam stearat; kompresi; eutektik; pati jagung; karakterisasi fisik.

\section{Pendahuluan}

Tablet merupakan bentuk sediaan yang paling banyak digunakan karena memberikan kenyamanan dan kemudahan dalam penggunaan, formulasi dan proses produksi, serta biaya produksi yang rendah $[1,2]$. Karakteristik tablet dipengaruhi oleh dua faktor, yaitu formulasi dan proses pembuatan tablet [3]. Berbagai energi, seperti energi termal dan mekanik, dihasilkan selama proses pembuatan tablet yang berpotensi menyebabkan interaksi fisik antar komponen di dalam formulasi [4]. Interaksi antar bahan aktif, atau satu bahan aktif dengan bahan tambahan, maupun antar bahan tambahan dapat terjadi selama tahap pengempaan [5].

Ibuprofen merupakan bahan aktif farmasi golongan anti-inflamasi non steroid dan banyak dijumpai dalam bentuk sediaan padat, seperti kaplet dan tablet $[6,7]$. Ibuprofen diketahui berinteraksi dengan asam stearat dengan membentuk campuran eutektik pada perbandingan $40-60 \%$ [8, 2] dan dapat terbentuk karena pengempaan [5]. Campuran eutektik merupakan campuran dua

\section{Article history}

Received: 28 Feb 2018 Accepted: 10 April 2018 Published: 30 April 2018

Access this article

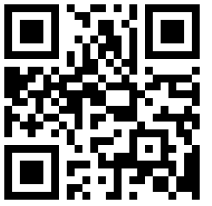


bahan dengan karakter titik lebur lebih rendah dari titik lebur masing-masing bahan penyusun campuran eutektik tersebut. Jika dalam suatu formulasi tablet terbentuk campuran eutektik, maka akan menyebabkan terbentuknya tablet yang lengket, perubahan kekerasan tablet, dan penurunan stabilitas sediaan [10].

Pati jagung dapat mencegah atau menurunkan terjadinya sintering (hilangnya batas antarpartikel) pada eritromisin stearat saat dikempa [11]. Pati jagung memiliki kandungan amilosa sebanyak 24-26\% dan amilopektin sebanyak 74-76\% [12]. Jumlah amilopektin di dalam pati akan memengaruhi nilai kekuatan tarik dan semakin rendah kekuatan tariknya semakin elastis sifat dari campuran massa cetak [13]. Pati jagung memiliki rantai dan gugus yang lebih panjang dengan berat molekul mencapai 50.000 sehingga mampu untuk meredam energi kompresi yang dapat menyebabkan interaksi yang tidak diinginkan [11].

Penelitian ini dilakukan untuk melihat pengaruh penambahan pati jagung terhadap penghambatan interaksi eutektik pada pengempaan campuran biner ibuprofenasam stearat. Penghambatan eutektikum dinilai dari hasil uji kekuatan mekanis dan karakterisasi fisik.

\section{Metode Penelitian}

\section{Bahan Penelitian}

Bahan-bahan yang digunakan dalam penelitian ini adalah ibuprofen (Shasun Chemicals and Drugs Ltd., India), asam stearat (Hense Chemicals Manufacture Ltd., China), dan pati jagung (pharmaceutical grade) dari Samyang Genex Co., China.

\section{Metode Penelitian}

Massa yang akan dikompresi dibuat terlebih dahulu dengan mencampur di dalam mortar ibuprofen dengan pati jagung dalam 3 komposisi berbeda yaitu 10, 20, dan $30 \%$ (b/b) dari campuran biner ibuprofen-asam stearat (perbandingan 40:60 (\% b/b), kemudian ditambahkan asam stearat. $500 \mathrm{mg}$ campuran selanjutnya dikempa pada gaya tertentu dan tablet hasil kempa inilah yang selanjutnya dievaluasi kekuatan mekanisnya dan dikarakterisasi lebih lanjut.

\section{Uji Kekuatan Mekanis}

$500 \mathrm{mg}$ campuran biner-pati jagung dalam berbagai komposisi pati jagung dikempa pada gaya 14,95, 19,93, dan $24,91 \mathrm{kN}$ yang ditahan selama sepuluh detik. Tablet kempa didiamkan selama satu hari untuk pemulihan elastis. Ketebalan dan diameter diukur untuk masing-masing tablet, serta kekerasan tablet diukur menggunakan alat hardness tester Erweka TBH 220. Kekuatan tarik ( $\sigma$ ) (kgf/ $\mathrm{cm}^{2}$ ) ditentukan dengan persamaan:

$$
\sigma=2 \mathrm{~F} / \mathrm{D} \mathrm{t}
$$

Keterangan:

$$
\begin{aligned}
& \mathrm{F}=\text { kekerasan tablet }(\mathrm{kgf}), \mathrm{D}=\text { diameter tablet }(\mathrm{cm}), \\
& \mathrm{t}=\text { ketebalan tablet }(\mathrm{cm}) .
\end{aligned}
$$

\section{Pola Difraksi Sinar-X Serbuk (DSXS)}

Difraktometer sinar-X serbuk (Phillips XPert, Netherland) digunakan untuk memperoleh pola difraksi sampel dengan pengaturan sebagai berikut: sumber radiasi $\mathrm{CuK} \alpha(1,54 \AA)$, pada $40 \mathrm{kV}$ and $30 \mathrm{~mA}$, dan sampel dibaca dengan kecepatan $0,017^{\circ} /$ detik pada rentang $2 \theta \quad 5-50^{\circ}$. Difraktogram yang diperoleh dianalisa menggunakan perangkat lunak Winplotr.

\section{Differential Thermal Analysis (DTA)}

Sekitar $5 \mathrm{mg}$ sampel (baik serbuk bahan awal maupun cuilan tablet kompresi) dimasukkan ke dalam pan aluminium sampel lalu dimasukkan ke dalam peranti DTA (Mettler Toledo FP 85, Swiss). Alat diatur dengan laju pemanasan $5^{\circ} \mathrm{C} /$ menit pada rentang suhu pemanasan $30-130^{\circ} \mathrm{C}$. Fenomena termal yang terjadi diamati melalui profil termogram yang dihasilkan.

\section{Spektroskopi Fourier Transform Infrared (F'T-IR)}

Sampel dicampur dengan serbuk $\mathrm{KBr}$ pro spektrofotometri di dalam mortir hingga homogen, kemudian dimasukkan ke dalam alat pembuat cakram $\mathrm{KBr}$ dan ditekan dengan pompa hidrolik hingga diperoleh cakram yang transparan. Masing-masing sampel direkam spektranya pada rentang bilangan gelombang 500-4000 cm-1 menggunakan alat spektrometer FT-IR Shimadzu 8400s, Jepang.

\section{Scanning Electron Microscopy (SEM)}

Analisis mikroskopi SEM dilakukan pada permukaan tablet kompresi campuran biner-pati jagung menggunakan perangkat Hitachi TM3000, Jepang, dengan perbesaran 1000 kali.

\section{Hasil dan Diskusi}

Uji kekuatan mekanik sebagai fungsi kekuatan tarik masing-masing bahan dan sampel campuran disajikan dalam grafik pada Gambar 1. Uji ini dilakukan untuk mengamati karakter mekanis dari ibuprofen, asam stearat, pati jagung, campuran biner ibuprofen-asam stearat, serta pengaruh penambahan pati jagung terhadap karakter mekanis campuran biner. Nilai kekuatan tarik tablet diperoleh dari harga kekerasan dan dimensi tablet [14]. 


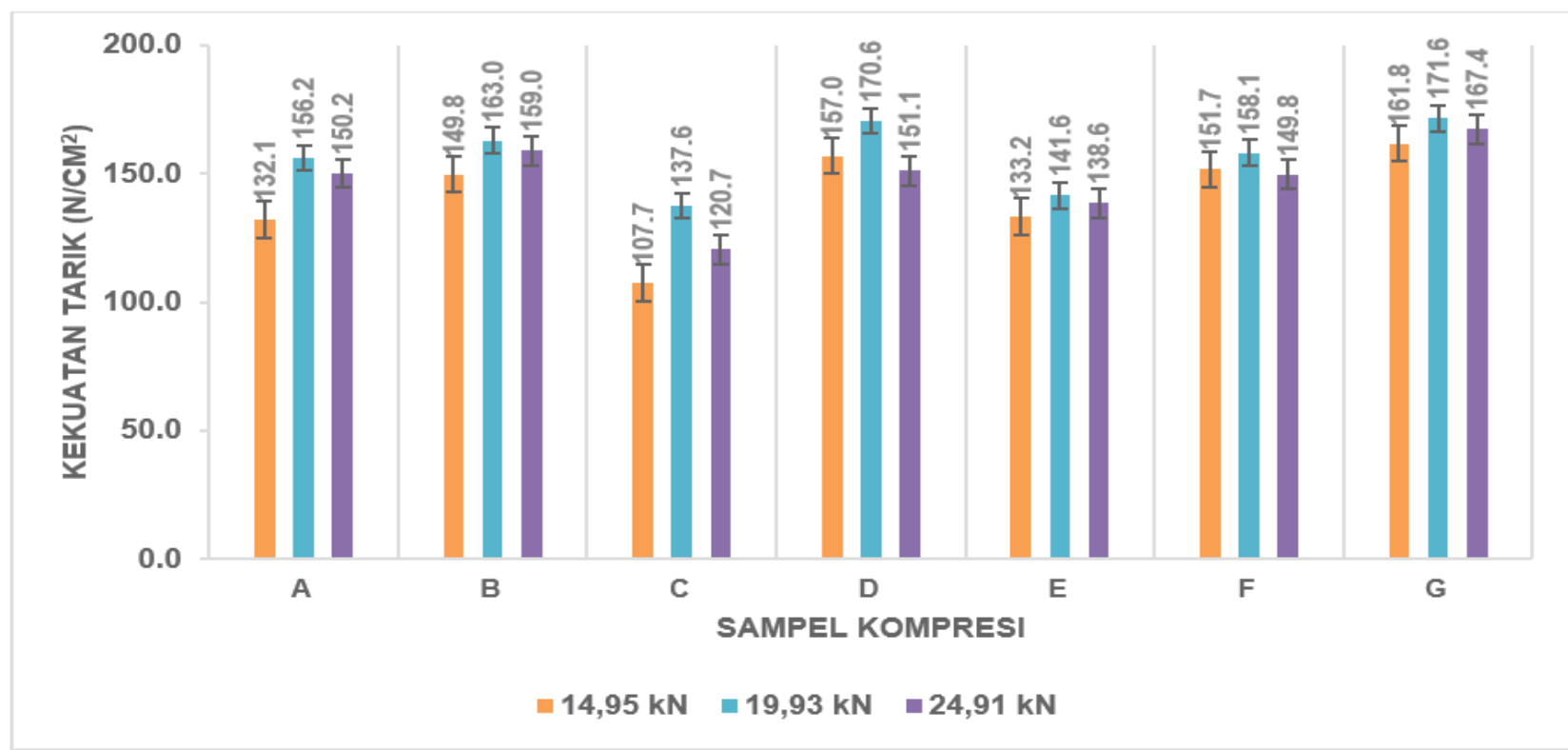

Gambar 1. Nilai kekuatan tarik pada berbagai gaya kompresi A. ibuprofen, B. asam stearat, C. pati jagung, D. campuran biner ibuprofen-asam stearat 40:60 (\% b/b), E. campuran ibuprofen-asam stearat-pati jagung 10\%, F. campuran ibuprofen-asam stearat-pati jagung 20\%, dan G. campuran ibuprofen-asam stearat-pati jagung 30\%.

Kompresi campuran biner ibuprofen-asam stearat (40:60 \%b/b) menunjukkan peningkatan nilai kekuatan dari masing-masing bahan awal (Gambar 1D). Peningkatan kekuatan tarik ini mengindikasikan terjadinya interaksi eutektik antar kedua bahan [5]. Interaksi eutektik dapat dicegah melalui penambahan bahan yang dapat meredam energi kompresi yang diterima. Salah satu contohnya adalah pati jagung yang memiliki komposisi amilopektin lebih rendah sehingga elastisitasnya lebih baik dari pati lain [13]. Elastisitas dari pati jagung inilah yang diharapkan mampu memberikan peredaman terhadap gaya kompresi.

Penambahan pati jagung 10 dan 20\% menyebabkan penurunan nilai kekuatan tarik dibandingkan campuran biner ibuprofen-asam stearat, namun hal yang sebaliknya terjadi pada penambahan 30\% (Gambar 1E-G). Hal ini kemungkinan disebabkan oleh peningkatan jumlah ikatan antarpartikel seiring dengan meningkatnya jumlah pati jagung yang ditambahkan [15]. Fenomena penurunan nilai kekuatan tarik yang terjadi pada penambahan pati jagung sebanyak 10\% dan 20\% menunjukkan bahwa pada komposisi tersebut interaksi eutektik ibuprofen-asam stearat oleh energi kompresi dapat dihambat.

Penelitian sebelumnya melaporkan bahwa karakter plastis campuran eutektik tertinggi pada komposisi ibuprofen-asam stearat 40:60 (\% b/b) dengan gaya kompresi 19,93 kN [5]. Oleh karena itu, perlakuan dengan gaya kompresi 19,93 $\mathrm{kN}$ dipilih untuk karakterisasi selanjutnya.



Gambar 2. Profil difraksi sinar-X serbuk A. ibuprofen, B. asam-stearat, C. pati jagung, D. kompresi campuran ibuprofen-asam stearat $(40: 60 \% \mathrm{~b} / \mathrm{b})$, E. kompresi campuran ibuprofen-asam stearat-pati jagung $10 \%(\mathrm{~b} / \mathrm{b})$, F. kompresi campuran ibuprofen-asam stearat-pati jagung $20 \%$, dan G. kompresi campuran ibuprofen-asam stearatpati jagung $30 \%$.

Analisis pola difraksi sinar-X serbuk dilakukan pada bahan awal dan campuran yang dikompresi. Analisis ini ditujukan untuk melihat interaksi kristal yang terjadi dalam campuran [16]. Kompresi campuran ibuprofen-asam stearat 40:60 (\% b/b) menunjukkan pergeseran puncak interferensi menuju sudut $2 \theta$ lebih kecil daripada bahan awal (Gambar 2D), seperti yang dilaporkan pada penelitian terdahulu [5]. Pergeseran puncak interferensi menandakan 
bahwa terjadi interaksi antara kedua bahan [16].

Pergeseran sudut difraksi menuju sudut lebih tinggi diperlihatkan oleh kompresi campuran ibuprofen-asam stearat-pati jagung $20 \%$ pada $2 \theta=11,2 ; 16,2$; dan $16,4^{\circ}$ (Gambar 2F, tanda panah) dengan intensitas yang semakin menurun. Penurunan intensitas puncak interferensi menunjukkan kemampuan pati jagung dalam mencegah interaksi antara ibuprofen dan asam stearat. Fenomena ini mengindikasikan bahwa penambahan pati jagung dengan komposisi $20 \%$ dari campuran ibuprofen-asam stearat secara efektif mampu mencegah interaksi antara kedua bahan. Oleh karena itu, penambahan pati jagung 20\% dipilih untuk karakterisasi lebih lanjut dengan metode lain.

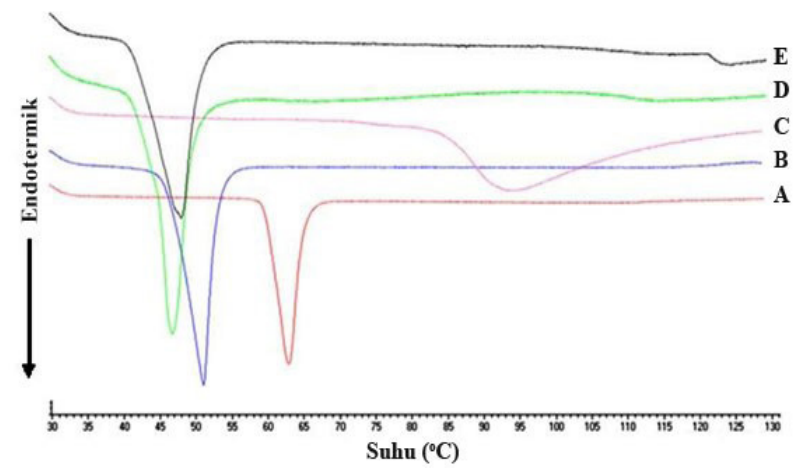

Gambar 3. Termogram A. ibuprofen, B. asam-stearat, C. pati jagung, D. kompresi campuran ibuprofen-asam stearat (40:60\%b/b), dan E. kompresi campuran ibuprofen-asam stearat-pati jagung $20 \%$.

Termogram DTA bahan awal dan kompresi campuran pada gaya 19,93 kN dapat dilihat pada Gambar 3. Ibuprofen, asam stearat, dan pati jagung memberikan puncak endotermik berturut-turut pada 77,8; 60,0; dan $125,9^{\circ} \mathrm{C}$. Kompresi campuran biner ibuprofen-asam stearat 40:60 (\% b/b) menunjukkan satu puncak endotermik yang merupakan titik lebur eutektik pada $54,1^{\circ} \mathrm{C}$ dengan entalpi peleburan sebesar 96,7 J/kg. Kompresi campuran binerpati jagung $20 \%$ memiliki titik lebur sebesar $56,0^{\circ} \mathrm{C}$ dengan entalpi peleburan sebesar 90,3 J/kg. Peningkatan nilai titik lebur menandakan pati jagung dapat meredam interaksi eutektik antara ibuprofen-asam stearat pada pengempaan.

Analisis spektroskopi FT-IR digunakan untuk membuktikan interaksi kimiawi yang terjadi [16]. Spektra inframerah masing-masing bahan dan campuran dapat dilihat pada Gambar 4. Penelitian sebelumnya menemukan bahwa kompresi campuran biner ibuprofen-asam stearat 40:60 (\% b/b) tidak memberikan perbedaan signifikan dari campuran biner yang tidak dikompresi [5]. Kompresi campuran biner-pati jagung 20\% menghasilkan spektrum FT-IR dengan pola serapan yang tidak berbeda dari kompresi campuran biner. Interaksi yang melibatkan pembentukan ikatan hidrogen dapat dideteksi jika terjadi perubahan puncak dan intensitas serapan [17].

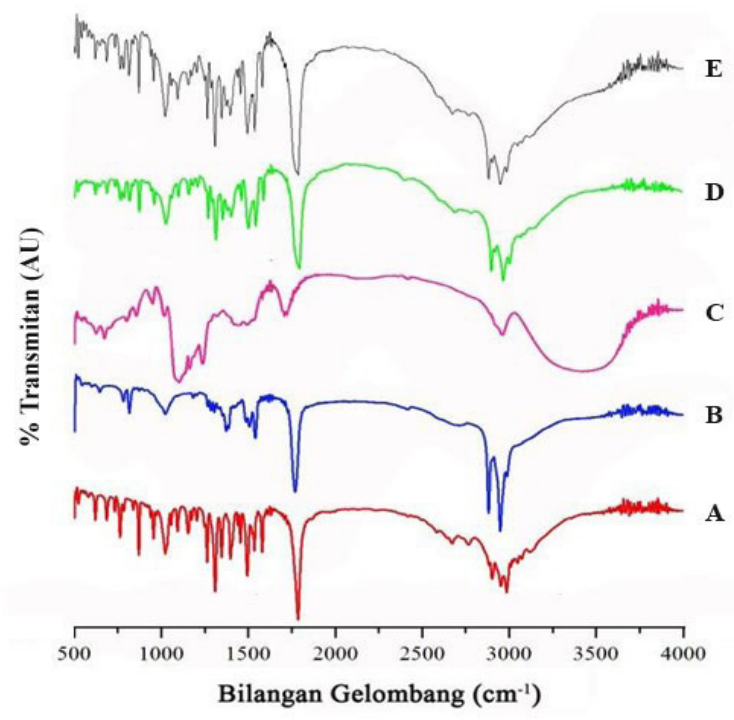

Gambar 4. Spektra inframerah A. ibuprofen, B. asam-stearat, C. pati jagung, D. kompresi campuran ibuprofen-asam stearat $(40: 60 \% \mathrm{~b} / \mathrm{b})$, dan E. kompresi campuran ibuprofen-asam stearat-pati jagung $20 \%$.

Analisis dengan elektron mikroskopi SEM dilakukan untuk melihat citra visual permukaan tablet kompresi bahan awal dan campuran. Masing-masing bahan awal memiliki bentuk habit kristal yang berbeda dan dapat dibedakan (Gambar 5A-C), namun pada pengempaan campuran ibuprofen dan asam stearat terjadi sintering [5] dan batas antarpartikel sudah tidak terlihat lagi (Gambar 5D). Penambahan pati jagung menghasilkan fotomikrograf struktur patahan pada daerah permukaaan dan partikel bulat pipih pati jagung terlihat di antara patahan (Gambar 5E). Gambaran fotomikrograf demikian menunjukkan elastisitas pati jagung dalam meredam energi kompresi yang digunakan ibuprofen dan asam stearat untuk berinteraksi.

\section{Kesimpulan}

Penambahan pati jagung ke dalam campuran biner ibuprofen-asam stearat 40:60 (\% b/b) dapat menghambat terjadinya interaksi eutektik pada pengempaan dengan penghambatan terbaik pada komposisi 20\% (b/b) pati jagung yang ditambahkan. Profil difraksi sinar-X serbuk menunjukkan pergeseran sudut ke nilai $2 \theta$ lebih tinggi dan penurunan intensitas interferensi. Analisis termal 
menunjukkan peningkatan titik lebur eutektik dan spektra FT-IR mengindikasikan tidak adanya interaksi antara pati jagung dengan asam stearat dan ibuprofen. Mikrofoto
SEM menunjukkan bahwa pati jagung terdispersi pada permukaan partikel ibuprofen dan asam stearat.
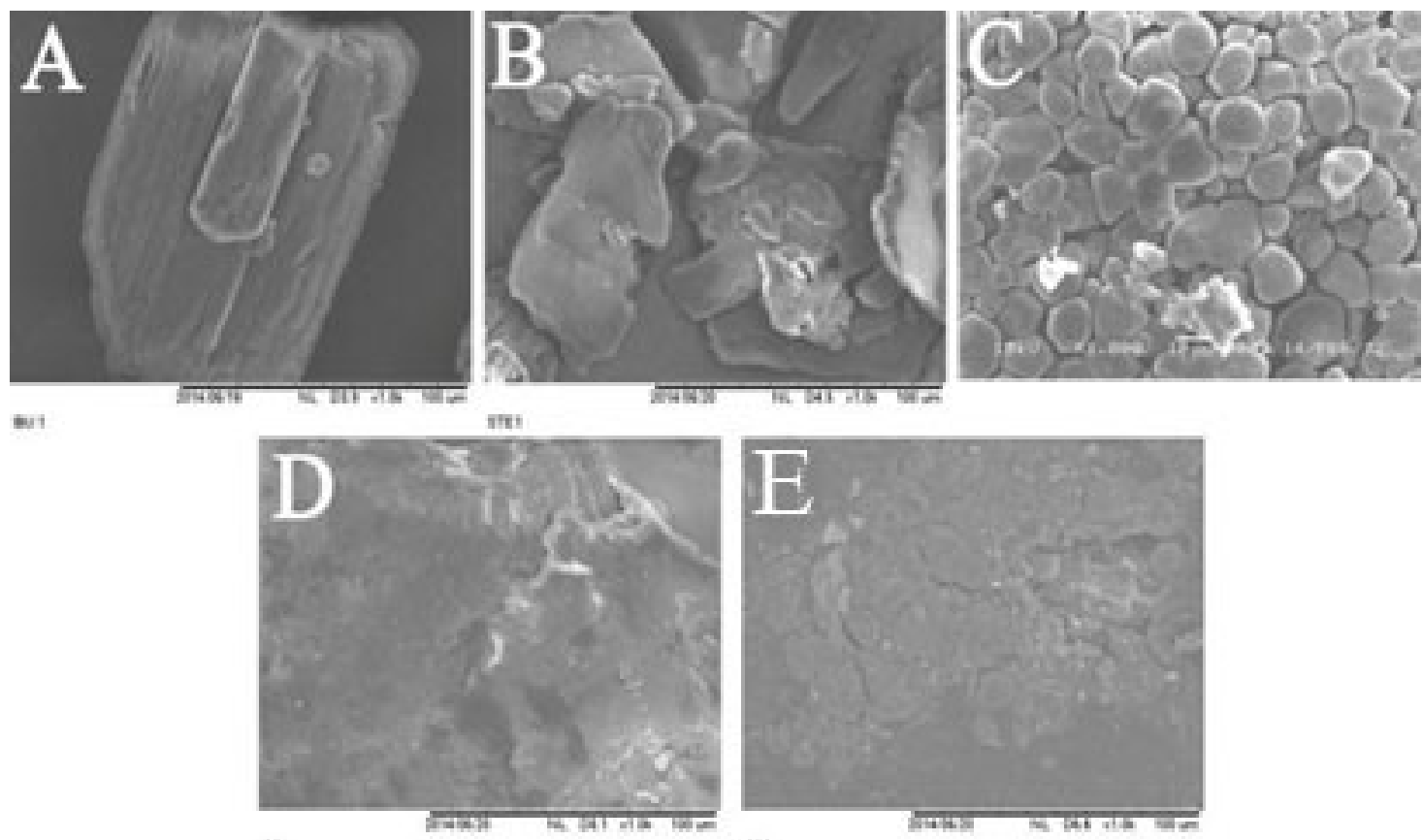

ai

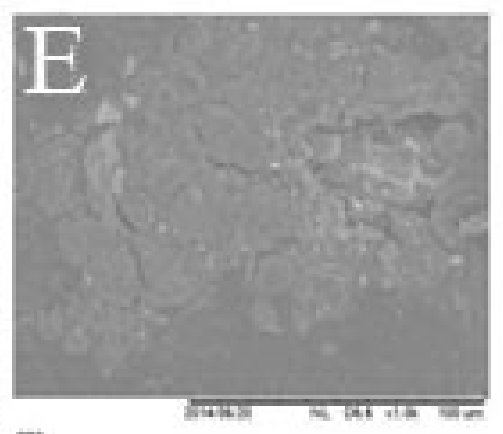

a:

Gambar 5. Fotomikrograf SEM pada perbesaran 1000 kali A. ibuprofen, B. asam-stearat, C. pati jagung, D. kompresi campuran ibuprofen-asam stearat (40:60 \% b/b), dan E. kompresi campuran ibuprofen-asam stearat-pati jagung $20 \%$.

\section{Referensi}

[1] Zhang, G. G. Z., Law, D., Schmitt, E. A., \& Qiu, Y. (2004). Phase transformation considerations during process development and manufacture of solid oral dosage forms. Advanced Drug Delivery Reviews, 56, 371-390.

[2] Setyawan, D., Widjaja, B., \& Sari R. (2013). Study on Crystallinity and Compactibility of Binary Mixture of Analgesic Substances with Microcrystalline Cellulose. International Journal of Pharmacy and Pharmaceutical Sciences, 5(3), 784-789.

[3] Mattsson, S. (2000). Pharmaceutical Binders and Their Function in Directly Compressed Tablets: Mechanistic Studies on the Effect of Dry Binders on Mechanical Strength, Pore Structure and Disintegration of Tablets. Uppsala: Acta Universitatis Upsaliensis.

[4] Hosaka, S., Sato, M., Ozawa, Y., Hamada, C., Takahashi, Y., \& Kitamori, N. (2005). Effect of compression on interaction between 1,4-dihydropyridine compounds and lactose monohydrate. Chemical and Pharmaceutical Bulletin, 53(5), 503-507.

[5] Setyawan, D., Isadiartuti, D., Betari, S. D., \& Paramita, D. P. (2016). Physical Characterization of Ibuprofen-Stearic Acid Binary Mixture Due to Compression Force. Indonesian Journal of Pharmacy, 27(1), 28-34.

[6] Sweetman, S. C. (2009). Martindale The Complete Drug Reference (36th ed.). London: The Pharmaceutical Press.

[7] Ikatan Apoteker Indonesia. (2010). ISO Informasi Spesialite Obat Indonesia Volume 46. Jakarta: Penerbit Ikatan Apoteker Indonesia.
[8] Lerdkanchanaporn, S., Dollimore, D., \& Evans, S. J. (2001). Phase diagram for the mixtures of ibuprofen and stearic acid. Thermochimica Acta, 367-368, 1-8.

[9] Paramita, D.P., Setyawan, D., \& Isadiartuti, D. (2014). Physical interaction study of ibuprofen-stearic acid binary mixture. Proceeding The 1st International Conference on Pharmaceutics \& Pharmaceutical Sciences, 59-62.

[10] Bi, M., Sung J. H., \& Kenneth R. M. (2003). Mechanism of Eutectic formation Upon Compaction and Its Effects on Tablet Properties. Thermochimica Acta, 404, 213-226.

[11] Setyawan, D. 2012. Pengaruh Variasi Kompresi dan Berbagai Jenis Eksipien Terhadap Karakterisasi Fisik Eritromisin Stearat dan Sediaan Tabletnya. Disertasi Program Doktor, Sekolah Farmasi ITB, Bandung.

[12] Singh, N., Sandhu, K.S., \& Kaur, M. (2005). Physicochemical properties including granular morphology, amylose content, swelling and solubility, thermal and pasting properties of starches from normal, waxy, high amylose and sugary corn. Progress in Food Biopolymer Research, 1, 44-54.

[13] Taghvaei-Ganjali, S., Motiee, F., \& Abbasian, A. (2010). Effect of Amylose/Amylopectin ratio on physico-mechanical. Journal of Applied Chemical Researches, 4(14), 53-60.

[14] Wu, C. Y., Best, S. M., Bentham, A. C., Hancock, B. C., \& Bonfield, W. (2005). A Simple Predictive Model for the Tensile Strength of Binary Tablets. European Journal of Pharmaceutical Sciences, 25, 331-336. 
[15] Van Veen, B., van der Voort Maarschalk, K., Bolhuis, G. K., Zuurman, K., \& Frijlink, H. W. (2000). Tensile strength of tablets containing two materials with a different compaction behaviour. International Journal of Pharmaceutics, 203, 71-79.

[16] Zaini, E., Halim, A., Soewandhi, S. N., \& Setyawan D. (2011). Peningkatan laju pelarutan trimetoprim melalui metode kokristalisasi dengan nikotinamida. Jurnal Farmasi Indonesia, 5(4), 205212.
[17] Putra, O.D., Nugrahani, I., Ibrahim, S., \& Uekusa, H. (2012) Pembentukan Padatan Semi Kristalin dan Ko-kristal Parasetamol. Jurnal Matematika dan Sains, 17(2), 83-88.

Copyright $\odot 2018$ The author(s). You are free to share (copy and redistribute the material in any medium or format) and adapt (remix, transform, and build upon the changes were made. You may do so in any reasonable manner, but not in any way that suggests the licensor endorses you or your use; ShareAlike - If you remix,
transform, or build upon the material, you must distribute your contributions under the same license as the original (https://creativecommons.org/licenses/by-sa/4.0/) 